livraisons

d'Histoire

de l'Architecture

\section{Livraisons de l'histoire de l'architecture}

36 | 2018

Jean-Louis Pascal (2)

L'architecte diocésain : travaux à la basilique SaintApollinaire de Valence

Works in the Saint-Apollinaire Basilica of Valence

Die Arbeiten an der Basilika Saint-Apollinaire in Valence

\title{
Anne Richard-Bazire
}

\section{OpenEdition}

Journals

Édition électronique

URL : http://journals.openedition.org//ha/1026

DOl : $10.4000 /$ /ha. 1026

ISSN : 1960-5994

Éditeur

Association Livraisons d'histoire de l'architecture - LHA

Édition imprimée

Date de publication : 15 décembre 2018

Pagination : $51-76$

ISSN : 1627-4970

Référence électronique

Anne Richard-Bazire, «L'architecte diocésain : travaux à la basilique Saint-Apollinaire de Valence », Livraisons de l'histoire de l'architecture [En ligne], 36 | 2018, mis en ligne le 15 décembre 2020, consulté le 25 janvier 2021. URL : http://journals.openedition.org/lha/1026 ; DOl : https://doi.org/10.4000/lha. 1026

Tous droits réservés à l'Association LHA 


\section{L'ARCHITECTE DIOCÉSAIN : TRAVAUX À LA BASILIQUE SAINT-APOLLINAIRE DE VALENCE}

En 1875, Jean-Louis Pascal est nommé architecte diocésain de Valence, en charge de la basilique Saint-Apollinaire, du séminaire et de l'évêché. C'est une consécration pour un architecte considéré comme "académique ", qui ne se situe pas dans la mouvance de Viollet-le-Duc et des architectes "néo-gothiques », ceux que l'on appelle les "diocésains». À Saint-Apollinaire de Valence, Pascal adopte une politique de restauration très respectueuse des apports des siècles passés ; c'est une nouveauté : «Pascal [...] fut un des premiers architectes qui respecta scrupuleusement l'œuvre des générations précédentes. Nous partageons tous aujourd'hui la manière de voir de mon maître [c'est Henri Nénot qui parle] et c'est cependant la première fois dans l'histoire de notre art que l'ensemble des artistes a le même scrupule ${ }^{1}$." La basilique cathédrale de Valence (ill. 1) se classe parmi les édifices religieux les plus anciens et les plus remarquables du midi de la France. Elle est désignée sous le vocable de Saint-Apollinaire, évêque de Valence de 486 à 520 ; elle a été élevée à la dignité de basilique mineure en 1847 en souvenir du pape Pie VI, mort à Valence le 29 août 1799.

\section{Histoire d'une basilique}

Charles Rohault de Fleury décrivait ainsi Saint-Apollinaire : "L'aspect de cette église est majestueux et présente un des plus magnifiques monuments romans ${ }^{2}$. Le chanoine Perrot, qui, le premier, réalisa une monographie de l'édifice en 1925, faisait remonter la construction de la nef au XI ${ }^{\mathrm{e}}$ siècle, celle du chœur, au XII ${ }^{\mathrm{e}}$ siècle $^{3}$. Michel Chevalier, dans La France des cathédrales, place la construction de l'église dans la deuxième moitié du XII siècle $^{4}$. Si l'édifice emprunte à l'architecture romane du Poitou sa technique de neutralisation des poussées, la voûte maîtresse étant contrebutée par de hauts collatéraux, et à l'école d'Auvergne et du Velay le vaste

1. Paul Henri Nénot, "La vie et les œuvres de Jean-Louis Pascal ", L'Architecture, 25 septembre 1921, p. 14.

2. Rohault de Fleury, Les saints de la messe, SS. Corneille et Cyprien, p. 189, cité par Chanoine J. Perrot, La Basilique de Saint-Apollinaire, Valence, imp. Jules Céas et fils, 1925, p. 6. Pour l'histoire de la cathédrale, voir aussi Chanoine Perrot et Noël Thiollier, La Cathédrale de Valence, SaintÉtienne, imp. Dumas, 1925, 30 p.

3. André Blanc pense au contraire que le chœur était déjà en place lors de la consécration de l'édifice en 1095. André Blanc, La Cathédrale de Valence, témoin de l’humanité romane, Valence, éd. peuple libre, 1984, p. 61.

4. Michel Chevalier, La France des cathédrales du $I V^{e}$ au XX siècle, Rennes, éd. Ouest France, 1997, p. 140 . 


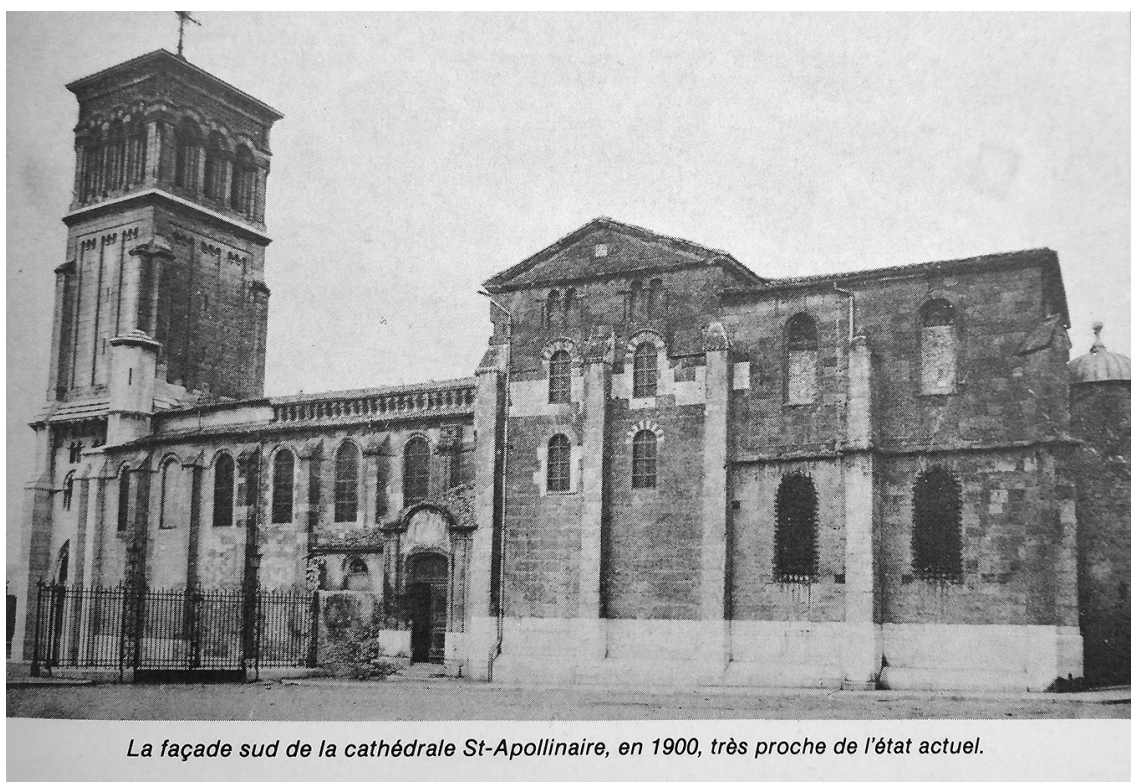

Ill. 1 : Cathédrale Saint-Apollinaire. Valence. Photo de la façade sud de la cathédrale, vue de la place des Ormeaux. André Blanc, La Cathédrale de Valence, témoin de l'humanité romane, Valence, éd. Peuple Libre, 1984, p. 64.

chœur à chapelles rayonnantes (ill. 2) et certains détails comme les contreforts du chevet affectant la forme de colonnes engagées avec socle, base et chapiteau très ornés, l'élément décoratif traduit l'influence provençale. On le voit sur les chapiteaux à l'intérieur, les frises, les frontons, les corniches de l'extérieur, mais particulièrement sur la porte méridionale, dont le tympan et le linteau sont visiblement inspirés du portail de Saint-Gilles du Gard.

L'édifice fut presqu'entièrement détruit au XVI ${ }^{\mathrm{e}}$ siècle. Le $1^{\mathrm{er}}$ novembre 1567 , les troupes protestantes mirent le feu à toutes les églises de la ville. Le chevet de Saint-Apollinaire fut démoli jusqu'à quelques pieds du sol, à l'exception de la partie touchant la sacristie, toutes les voûtes effondrées ayant entrâné quatorze grands piliers sur seize. Ne restaient debout que les murs latéraux des nefs et du transept ${ }^{5}$.

En 1604, la restauration de la cathédrale est confiée à l'architecte Jehan Thuillier et au maître-maçon Jacques Blanc. L'année 1607 voit s'achever les voûtes des nefs de Saint-Apollinaire mais on renonce au dôme surmonté d'un lanternon qui devait s'élever à la croisée du transept. Au mois d'août 1609 le chœur était reconstruit. En 1611, on décide de reconstruire la clôture du chœur. Les stalles sont réalisées en 1618 par un menuisier de Montélimar: Jean-Jacques Panis ${ }^{6}$. Reconstruction remarquable, selon Guy Barruol pour lequel : « Le travail des artisans du XVII ${ }^{\mathrm{e}}$ siècle

5. Chanoine J. Perrot, La Basilique de Saint-Apollinaire, op. cit., p. 141.

6. Ibid., p. 171. 


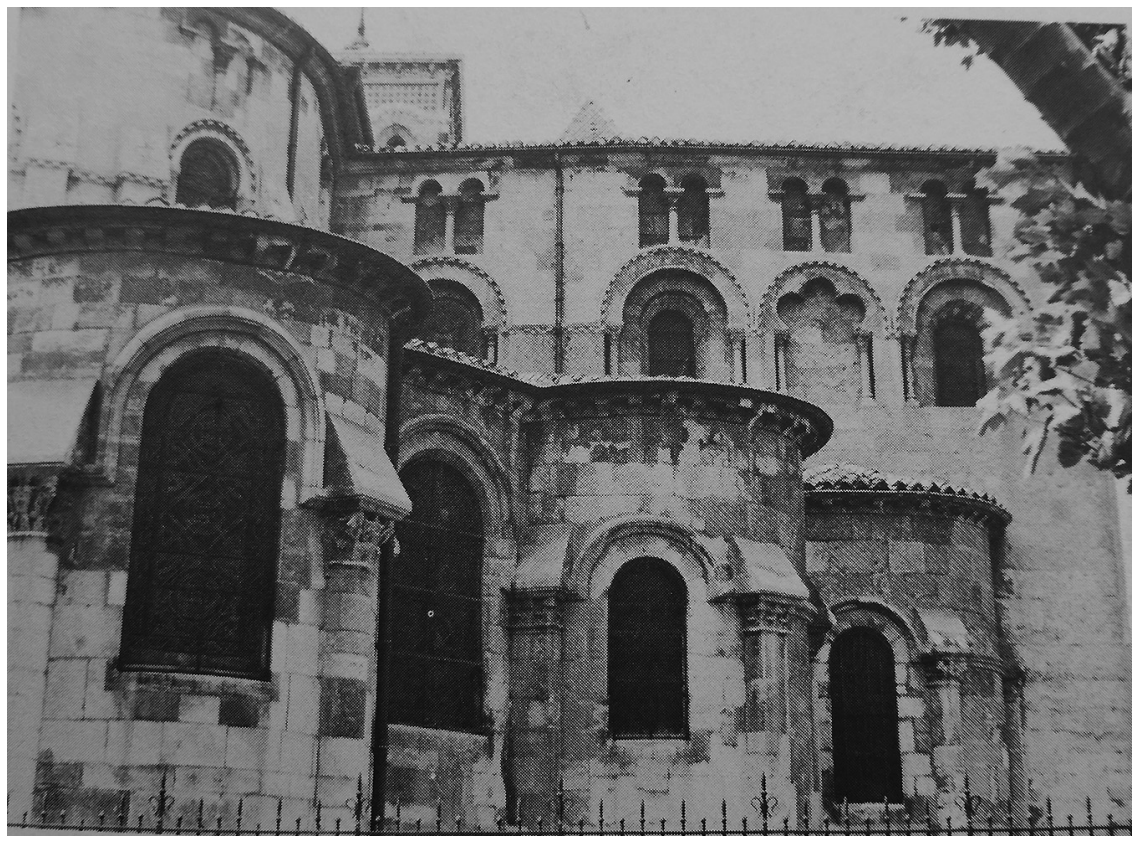

Ill. 2 : Le chevet de la cathédrale de Valence. Vue des absidioles nord-est avec l'alternance de colonnes et de pilastres engagés. Sur la face est du bras nord du transept, l'unique fenêtre trilobée. André Blanc, La Cathédrale de Valence, témoin de l'humanité romane, Valence, éd. Peuple Libre, 1984, p. 74.

[y] est parfait et quasiment identique à celui des constructeurs romans ", qu'il s'agisse de l'origine des matériaux, de l'outillage ou du « savoir-faire traditionnel » 7 .

En 1726, Alexandre Milon de Mesmes devient évêque de Valence et décide de transformer l'édifice selon la mode de l'époque, transformation confiée à l'architecte Blanc et à un entrepreneur de Tournon nommé Trompet. Le pavé de la nef est relevé de $0,50 \mathrm{~m}$ et celui du chœur est abaissé ; on réalise tout le pavage de l'église en losanges blancs et noirs. Des hauteurs d'appui en pierre noire polie et lustrée surmontées d'une grille en fer forgé ferment le chœur sur les côtés. La colonnade qui entoure le chœur est noyée dans un épais massif de mortier. Les stalles sont ramenées de l'avant à l'arrière du chœur. En 1757, Mgr Milon commande à Lyon un maitre-autel en forme de tombeau avec deux crédences en marbre, dessiné par le peintre et architecte lyonnais Treilhard. Jusque-là placé dans l'abside, il est avancé et le trône épiscopal placé au fond de l'abside, entouré par les stalles. Les voûtes du chœur sont recouvertes d'un mortier enduit d'un blanc poli et lustré et les arcs des voûtes peints dans le ton de la pierre de taille agrémentée de filets blancs. On ouvre des portes d'accès à l'église dans la dernière travée des collatéraux ${ }^{8}$ (ill. 3).

7. Michel Chevalier, La France des cathédrales, du IVe au XXe siècle, op. cit., p. 194.

8. Les portes d'accès initiales s'ouvraient sur la face ouest des bras du transept; elles sont murées en 1731 . 


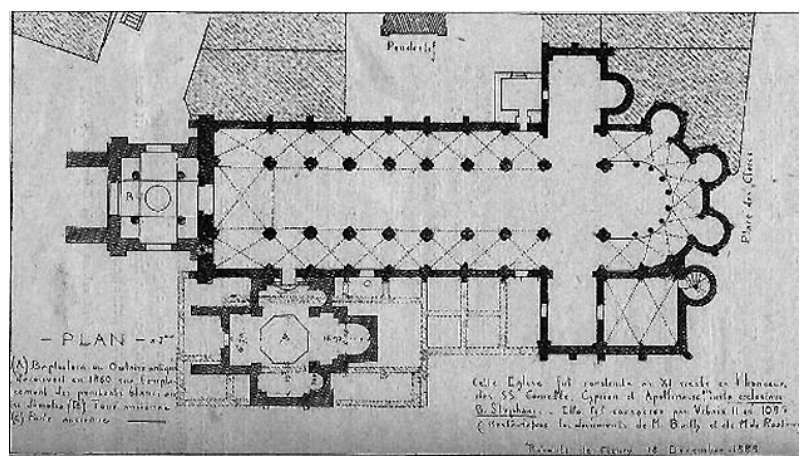

Ill. 3 : Plan de la cathédrale de Valence construite aux $\mathrm{XI}^{\mathrm{e}}$ et $\mathrm{XII}^{\mathrm{e}}$ siècles, avec son ancien clocher et le baptistère Saint-Jean, d'après Rohault de Fleury, 18 décembre 1889. J. Perrot (Chanoine), La Basilique de Saint-Apollinaire, Valence, imp. Jules Céas et fils, 1925, p. 64.

Des tambours en pierre de taille recouverts de tuile sont créés au-dehors de chaque porte de côté de l'église (ill. 4), et on établit, devant la porte des tambours, un perron d'une marche, pour garantir l'église des eaux de pluie. L'ouverture d'une porte de la sacristie sur le bras sud du transept nécessite la démolition de l'escalier menant à la salle capitulaire et son report au dehors, dans une tour ronde placée derrière la sacristie (ill. 5). Transformée en prison puis en Temple de la Raison pendant la Révolution française, l'église voit son chevet peu à peu défiguré par des échoppes venues s'installer contre son mur (ill. 6).

Dans les années 1840, on dégage les abords de la cathédrale qui se trouvait cernée de toutes parts (ill. 7) : les échoppes du chevet disparaissent en 1843. La maison Courthial, qui jouxtait l'angle N.-O. du clocher, est démolie en 1851. L'église Saint-Étienne, devenue chapelle des Pénitents (bâtie sur les fondations d'un baptistère paléochrétien ${ }^{9}$ ), s'étendait contre la paroi extérieure du collatéral sud presque jusqu'au transept (ill. 3 et 8). En 1858, l'architecte Antoine Nicolas Bailly, architecte diocésain de Valence depuis 1850, en obtient la démolition. En 1891, la maison Milhan (ill. 6 et 7) qui obstruait la partie N.-O. de l'abside et le côté oriental du transept nord est démolie. Deux immeubles subsistaient, la maison Veuve Monneron et la maison Jouve, s'appuyant sur toute la largeur du transept au nord ${ }^{10}$.

\section{Extérieur de la cathédrale}

Les murs de la basilique sont construits en moyen appareil avec de la molasse de Châteauneuf d'Isère et ne comportent d'autres saillies que celles des contreforts marquant la division des travées intérieures. Ces contreforts au nombre de huit de

9. Voir Arch. nat., $\mathrm{F}^{19}$ 7915, Rapport à la société d'archéologie de la Drôme sur la découverte du baptistère de Valence et de sa mosä̈que, Valence, imp. de Chenevier et Chavet, 1866, 14 p. et Chanoine J. Perrot, La Basilique de Saint-Apollinaire, op. cit., p. 36-47. Michel Chevalier pense que les mosaïques du "baptistère hypothétique" de Valence sont une œuvre romane. Michel Chevalier, La France des cathédrales du IV au XX $X^{e}$ siècle, op. cit., p. 113.

10. Chanoine J. Perrot, La Basilique de Saint-Apollinaire, op. cit., p. 230-234. 


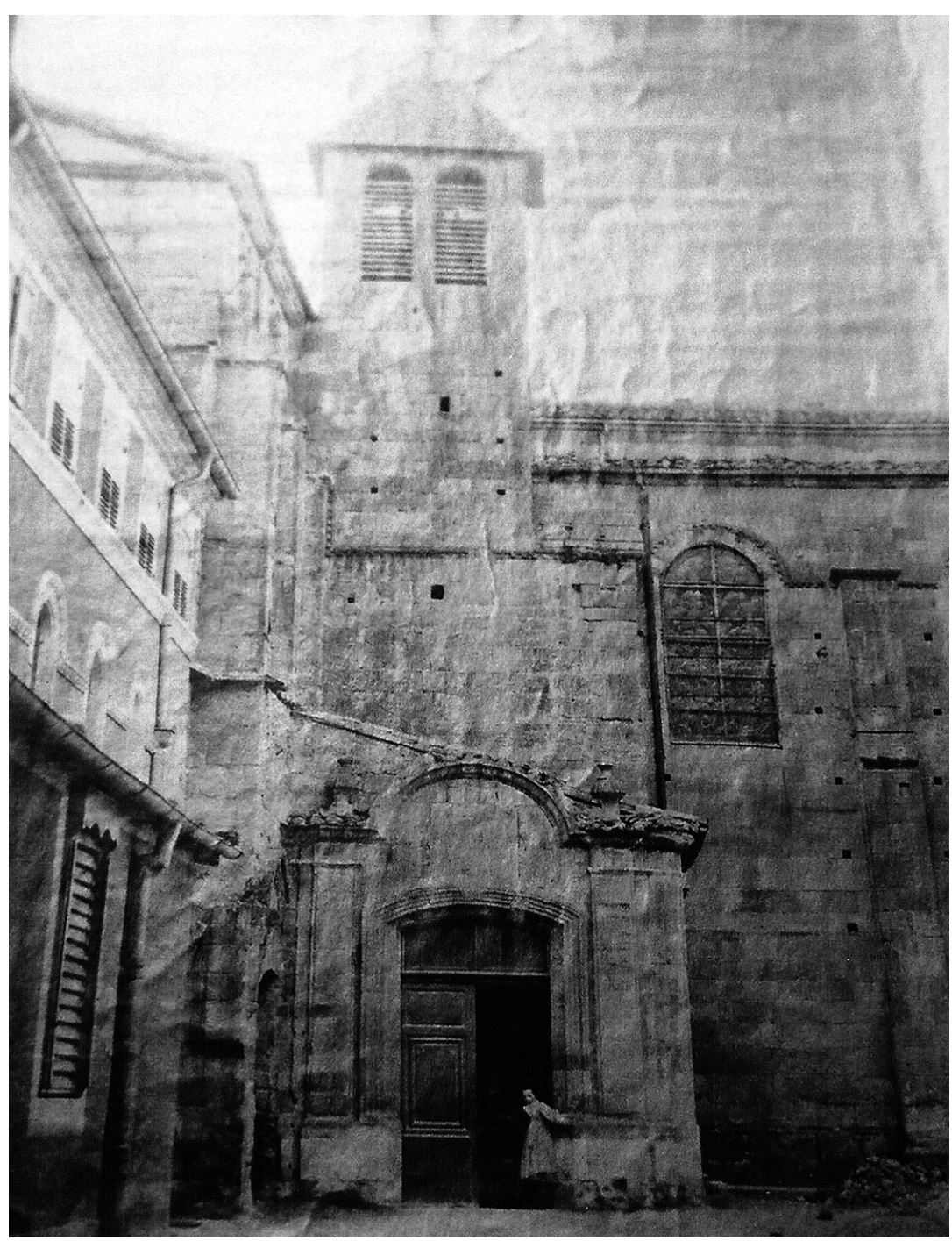

Ill. 4 : Cathédrale Saint-Apollinaire. Valence. Vue du porche nord qui masque une $1^{\text {re }}$ porte latérale de la cathédrale, quand l'entrée se faisait sur les bras du transept. Arch. nat. CP F ${ }^{19} 7915$. Cl. auteur.

chaque côté montent d'un seul jet jusque sous la corniche des collatéraux. Au milieu de chaque travée, entre les contreforts, s'ouvrent de hautes et larges fenêtres. Au-dessus des cintres de ces baies une alternance de pierres blanches et ocre agrémente la façade. Un cordon à billettes contourne leurs archivoltes et vient cravater les contreforts au-dessous du talus rampant de leur sommet ${ }^{11}$. Chaque nef possède sa toiture

11. Chanoine J. Perrot, La Basilique de Saint-Apollinaire, op. cit., p. 287. 


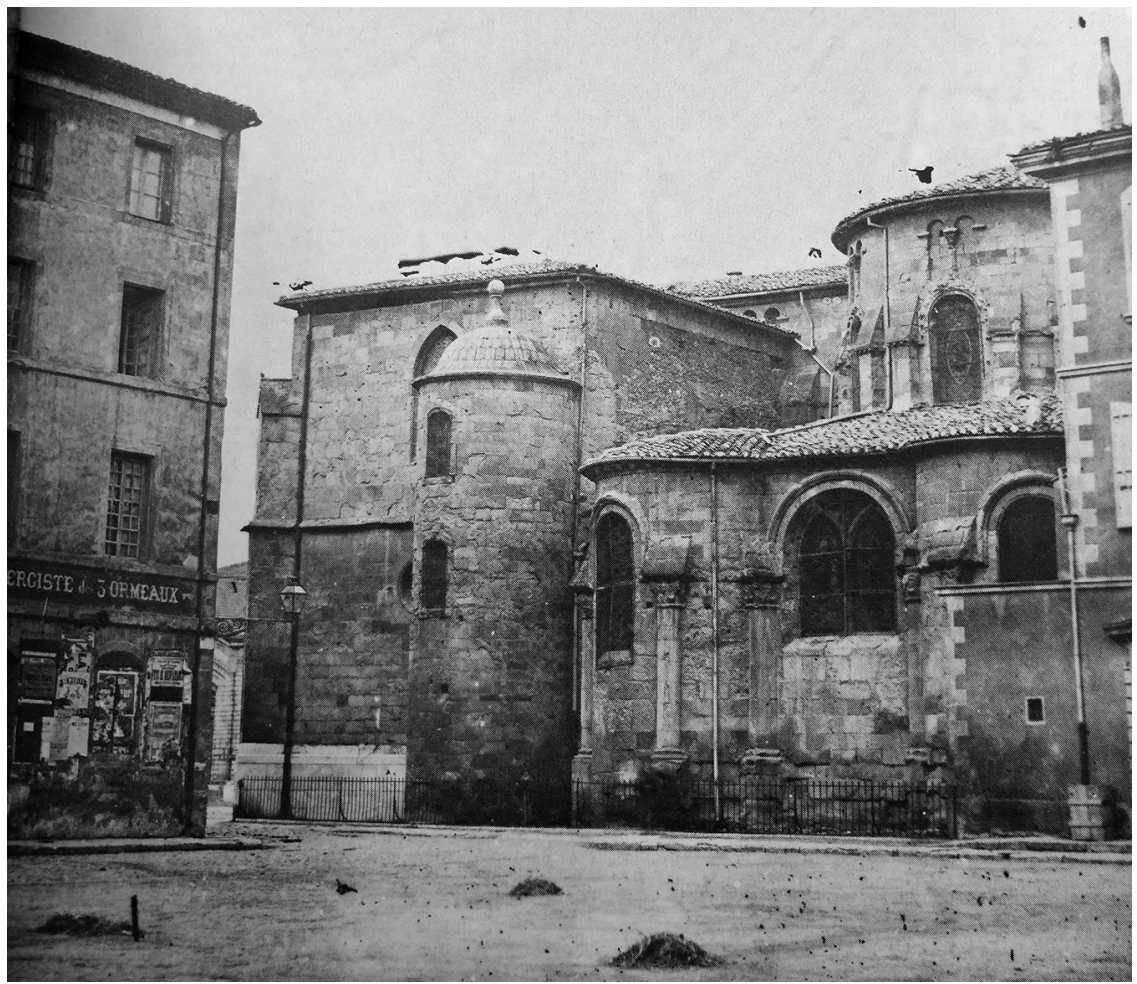

Ill. 5 : Détails de la cathédrale Saint-Appolinaire de Valence. Le chevet non encore dégagé : à droite la maison Milhan; à gauche du chevet, la sacristie et sa tourelle extérieure (escalier). André Blanc, $L a$ Cathédrale de Valence, témoin de l'humanité romane, Valence, éd. Peuple Libre, 1984, p. 77.

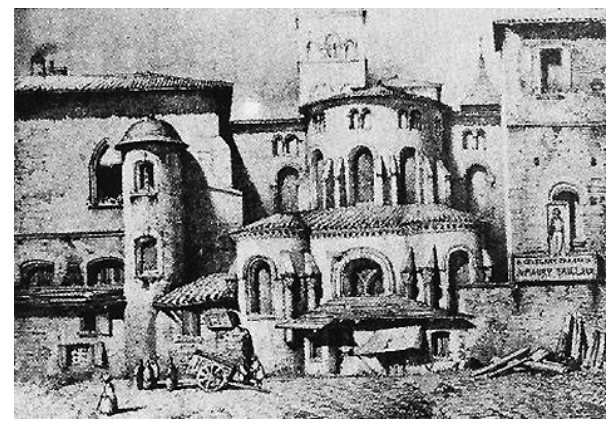

Ill. 6 : Détails de la cathédrale Saint-Apollinaire de Valence. Le chevet de la cathédrale Saint-Apollinaire de Valence enchâssé au milieu des boutiques. Gravure du début du XIX ${ }^{e}$ siècle. À droite la maison Milhan ; à gauche du chevet, la sacristie et sa tourelle extérieure. André Blanc, La Cathédrale de Valence, témoin de l'humanité romane, Valence, éd. Peuple Libre, 1984, p. 81. 
indépendante et dans la partie du mur sud ${ }^{12}$ émergeant au-dessus de la toiture du collatéral, s'ouvre une galerie à jour (ill. 1), appelée "galerie de couronnement" alternant arcs en plein cintre et en mitre. Viollet-le-Duc, à l'article "galerie " de son Dictionnaire raisonné de l'architecture française, explique ainsi l'apparition de ce motif décoratif: "Les voûtes en berceau laissaient entre leurs reins et le niveau de la corniche un mur nu d'un aspect désagréable et d'une grande pesanteur. On perça le mur par une galerie à jours ou fermée par un mur mince, destinée à donner de l'air aux combles. Cette disposition inspirée d'abord par un calcul de construction devint un motif de décoration dans quelques monuments religieux de France ». On en trouve en effet dans un assez grand nombre d'églises des bords du Rhin, dans quelques-unes de l'est de la France, à Autun par exemple, en Provence très rarement.

La hauteur du transept est la même que celle de la nef, sauf à la croisée, où émerge légèrement un carré de maçonnerie, souche du dôme aujourd'hui disparu.

Chaque côté des bras du transept, sauf celui qui regarde à l'est, est muni de trois contreforts et de trois rangs de fenêtres superposés. En haut, des fenêtres géminées aveugles avec colonnette au milieu; au-dessous deux rangées de simples fenêtres, plus grandes et plus ornées: elles s'ouvrent entre deux colonnettes à chapiteaux supportant une archivolte à claveaux alternés soulignée en bas d'un boudin et en haut d'un cordon à billettes. La fenêtre médiane du bras nord au levant est trilobée (ill. 2).

Le caractère décoratif du chevet contraste avec la simplicité du reste de l'édifice. La partie haute du chevet qui abrite le chœur est percée de cinq fenêtres de même dimension et situées à la même hauteur que la seconde rangée des fenêtres du transept; elles sont néanmoins dépourvues d'archivoltes supportées par des colonnettes; seul subsiste le cordon de billettes. Au-dessus, on retrouve les petites arcades géminées du transept, mais elles sont moins profondes.

La partie basse de l'abside (ill. 2), en forte saillie sur la partie haute, renferme le déambulatoire autour duquel s'accrochent les chapelles circulaires, trois au déambulatoire, une au bras nord du transept. Chaque chapelle est éclairée par une grande fenêtre, de même que les espaces compris entre deux chapelles. Au fond de l'axe de l'église une large fenêtre est divisée en deux par un meneau délimitant deux baies à arcs brisés ${ }^{13}$. Chaque chapelle est munie de contreforts ayant la forme de colonnes ou pilastres engagés, avec socle, base et chapiteau décoré d'acanthes, surmontés d'un talus rampant.

\section{Le plan}

L'église est de plan basilical (ill. 3), se terminant en hémicycle autour duquel règne un déambulatoire sur lequel s'ouvrent trois chapelles rayonnantes (la quatrième ayant disparu lors de l'adjonction au $\mathrm{XV}^{\mathrm{e}}$ siècle, par l'évêque Antoine de Balzac,

12. Au nord, la restauration de 1604 n'a pas rétabli cette disposition. Au sud, les arcs correspondant aux première et deuxième travées ont été supprimés au XIX ${ }^{e}$ siècle au cours de la reconstruction du clocher.

13. Chanoine J. Perrot, La Basilique de Saint-Apollinaire, op. cit., p. 293. 
de la sacristie). Sur un transept saillant s'ouvre au nord une chapelle orientée, celle du bras sud ayant aussi disparu lors de l'adjonction de la sacristie. Un clocherporche commande l'entrée principale de l'église, à l'ouest. À l'intérieur le vaisseau est divisé en trois nefs par seize piliers cantonnés de colonnes engagées, qui divisent l'espace dans le sens de la longueur en huit travées. Des arcs doubleaux à section rectangulaire marquent les divisions des travées dans les voûtes, qui sont d'arêtes dans les bas-côtés. Le déambulatoire est séparé du chœur par huit colonnes cylindriques et deux gros piliers semblables à ceux des nefs. La sacristie contient deux salles superposées divisées chacune en deux travées voûtées d'ogives. On accède à l'étage supérieur par un escalier à vis extérieur enfermé dans une tour ronde placée au N.-E. de la sacristie (ill. 5).

\section{Le clocher-porche}

La foudre avait frappé plusieurs fois le vieux clocher ${ }^{14}$ de Saint-Apollinaire (ill. 8) qui fut, malgré diverses réparations, démoli en 1839 par l'architecte valentinois Chevillet. En 1846, on décida de le reconstruire et les fouilles pour les fondations commencèrent. Il fallait les porter à une très grande profondeur car le clocher était tout au bord de la falaise, et ceci d'autant plus que des sondages sous le mur de la façade à l'ouest avait révélé leur insuffisance : elles ne descendaient pas à plus de deux mètres dans le sol. Dans un rapport de l'architecte diocésain Alexandre François Épailly ${ }^{15}$ (1811-1889) du 6 avril $1848^{16}$, celui-ci indique qu'il faut démolir les restes de l'ancienne tour et descendre jusqu'à $11 \mathrm{~m}$ en contrebas du rez-de-chaussée afin d'établir solidement les bases de la nouvelle construction. Un massif de béton sera coulé à l'emplacement de l'ancienne tour ${ }^{17}$. Épailly va proposer plusieurs projets de reconstruction du clocher; dans un premier projet, la tour présentait trois étages au-dessus des voûtes de la nef et était couverte d'une toiture plate identique à celle restaurée après l'incendie de 1822 ; le projet ne fut pas admis. Dans un second projet, la tour était surmontée d'une toiture pyramidale semblable à celle qui avait existé jusqu'en 1822 ; la forme et la hauteur de la pyramide était conforme aux toitures pyramidales d'anciennes églises d'Auvergne. Viollet-le-Duc fit un rapport ${ }^{18}$ à la commission des édifices religieux :

«Le projet examiné à plusieurs reprises par le conseil des bâtiments civils avait été l'objet d'observations assez graves, observations auxquelles M. l'architecte

14. C'était un clocher à six étages, en retrait les uns par rapport aux autres, le sixième correspondant à la flèche terminale. Il était construit sur une base carrée massive, ouvrant sur chacune de ses faces par une grande baie cintrée donnant accès à un porche.

15. En 1849, il est remplacé par Antoine-Nicolas Bailly pour incompétence, comme architecte diocésain de Valence. Il est néanmoins confirmé comme inspecteur de la cathédrale de Valence, sur proposition de Bailly, par un arrêté du 9 février 1854. Pascal le propose en 1887 aux palmes académiques comme "modèle d'honneur professionnel sous toutes ses formes ". Jean-Michel Leniaud, Les Cathédrales au XIX siècle, Paris, Economica, 1993, p. 683-684.

16. Arch. nat., $\mathrm{F}^{19} 7914$.

17. Un cube de $1000 \mathrm{~m}$ sur une surface de $300 \mathrm{~m}^{2}$.

18. Arch. nat., $\mathrm{F}^{19} 7914$. 
ne s'est conformé qu'en partie. Le conseil avait demandé en principe dans un premier avis, que le clocher moderne reproduisit exactement le clocher démoli, or le projet de M. l'architecte n'a que peu de rapport avec cet état ancien [...] Dans le devis, [...] il est question d'abat-jours en forme de persiennes fabriquées en tôle, de gouttières en fer blanc peint, ou en zinc; il ne me semble pas possible d'appliquer à un monument des objets de cette nature qui sont à peine admis dans les constructions particulières les plus vulgaires. Je crois que l'attention de M. l'architecte devra être appelé sur ces points importants, il ne peut ignorer qu'un monument se distingue surtout des constructions passagères, non par le plus ou moins de richesse des sculptures, mais par le soin apporté dans l'étude et l'exécution de toutes les parties qui assurent la conservation de l'édifice ".

Viollet-le-Duc voulait que la tour fût couronnée par un toit en pavillon plat couvert en tuiles creuses ou en plomb. Épailly se défendit en arguant que les façades de la nouvelle tour au-dessous des voûtes de la nef reproduisaient l'architecture de l'ancienne. Les différences se trouvaient au rez-de-chaussée, le rapporteur au conseil des bâtiments civils ayant jugé convenable de disposer des bandeaux et corniches de manière à les rattacher à ceux de la façade de l'église, de supprimer les saillies formées par les contreforts et de dessiner des portes plus hautes et plus ornées que les anciennes, le dégagement des abords de la cathédrale devant leur rendre leur fonction d'entrée principale ${ }^{19}$.

Les travaux étaient stoppés depuis le début de l'année 1848 ; Mgr Pierre (17951857), évêque de Valence depuis 1840, s'en inquiéta auprès du ministre de l'instruction publique et des cultes :

"On a voulu reprendre la façade en sous-œuvre, [...] l'humidité la pénètre de toutes parts. Elle a déjà subi un mouvement constaté par l'architecte dans un rapport au préfet du 24 janvier 1848, mouvement qui nécessitera sans doute la démolition de la tribune des orgues qui est adossée à cette façade. La solidité de la voûte est aussi compromise dans la partie antérieure. ${ }^{20}$

La ruine du mur de façade menaçait en outre l'école des Frères abritant quatre cents enfants, qui était située en contrebas de la façade ouest de l'église ${ }^{21}$.

Le 9 mai 1849, on confie les travaux au nouvel architecte Antoine-Nicolas Bailly. Épailly restait chargé de l'entretien des bâtiments du séminaire et de l'évêché, même s'il était remplacé dans la conservation des édifices diocésains de Valence ${ }^{22}$.

19. Ibid., lettre de l'architecte Épailly datée du 13 août 1848 , en réponse au rapport de la commission des édifices religieux.

20. Ibid., lettre de Mgr Pierre, évêque de Valence, au ministre de l'instruction publique et des cultes, 17 février 1849.

21. Ibid., lettre du préfet de la Drôme au ministre de l'instruction publique et des cultes, 26 janvier 1849.

22. Ibid., lettre du préfet de la Drôme au ministre de l'instruction publique et des cultes, 4 juillet 1849. 


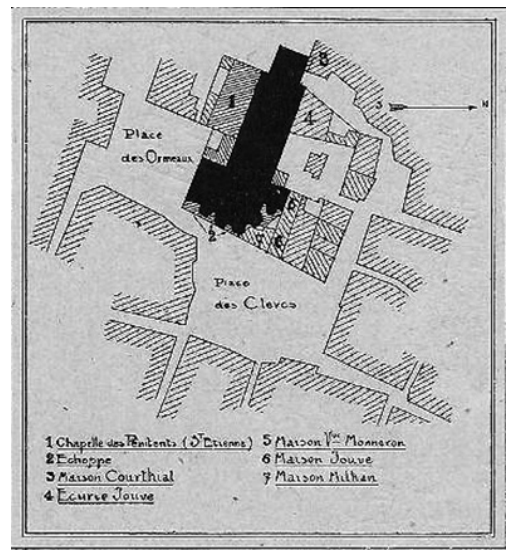

Ill. 7 : Cathédrale Saint-Apollinaire. Valence. Plan des abords de la cathédrale de Valence. J. Perrot (Chanoine), La Basilique de Saint-Apollinaire, Valence, imp. Jules Céas et fils, 1925, p. 231.

Les travaux s'arrêtèrent à nouveau en 1854 : "Le porche épaulé de solides contreforts percé sur trois faces de grandes portes surmontées de deux rangées de fenêtres semblables à celles du transept, entièrement construit en grand appareil de pierres de Crussol, et couronné d'une large corniche saillante portée sur des modillons à figures grimaçantes, atteignaient à ce moment le niveau de la naissance du toit de la grande nef $"{ }^{23}$. En 1858, une lettre du ministère de l'instruction publique et des cultes $^{24}$ invite l'architecte diocésain à terminer ses constructions par l'addition d'un étage destiné à recevoir le beffroi et "pour lesquelles il devra adopter des dispositions analogues à celles du clocher central de l'église d'Ainay à Lyon " ${ }^{25}$.

Les travaux reprennent en 1859 grâce à un crédit de 206972 francs. Deux étages restaient à élever au-dessus du porche. Le premier est très élevé et très simple : ses faces sans ouvertures, à part deux meurtrières, sont décorées de trois bandes lombardes rectangulaires. L'étage supérieur, moins élevé, est percé sur chacune de ses faces de trois ouvertures, longues et étroites, à doubles voussures retombant sur des colonnettes à chapiteaux, un cordon de billettes contournant les archivoltes. Entre celles-ci et la corniche à modillons, un panneau décoré de plaques de marbre disposées géométriquement à la manière auvergnate. Une toiture basse à quatre pans est surmontée d'une grande croix en fer forgé dorée et d'un coq. Le gros œuvre était terminé en

23. Chanoine J. Perrot, La Basilique de Saint-Apollinaire, op. cit., p. 247 et Arch. nat., $\mathrm{F}^{19} 7914$, affaires à soumettre à l'examen du comité des inspecteurs généraux des édifices diocésains, signé Léon Vaudoyer.

24. Arch. nat., $\mathrm{F}^{19} 7914$, lettre du ministre de l'instruction publique et des cultes au préfet de la Drôme, 18 mai 1858 .

25. Il s'agit de la basilique Saint-Martin d'Ainay dont le clocher-porte date du $\mathrm{XI}^{\mathrm{e}}$ siècle (la voûte est du XII ${ }^{\mathrm{e}}$ siècle et le tympan du XIX ${ }^{\mathrm{e}}$ siècle). Il présente au-dessus du porche d'entrée à arc brisé, trois étages agrémentés d'arcatures allongées qui vont en diminuant; aux premier et deuxième étages, les archivoltes des trois arcatures sont composées de claveaux alternés rouges (briques) et blancs. Si Bailly s'en est inspiré, c'est seulement pour le dernier étage de son porche. 


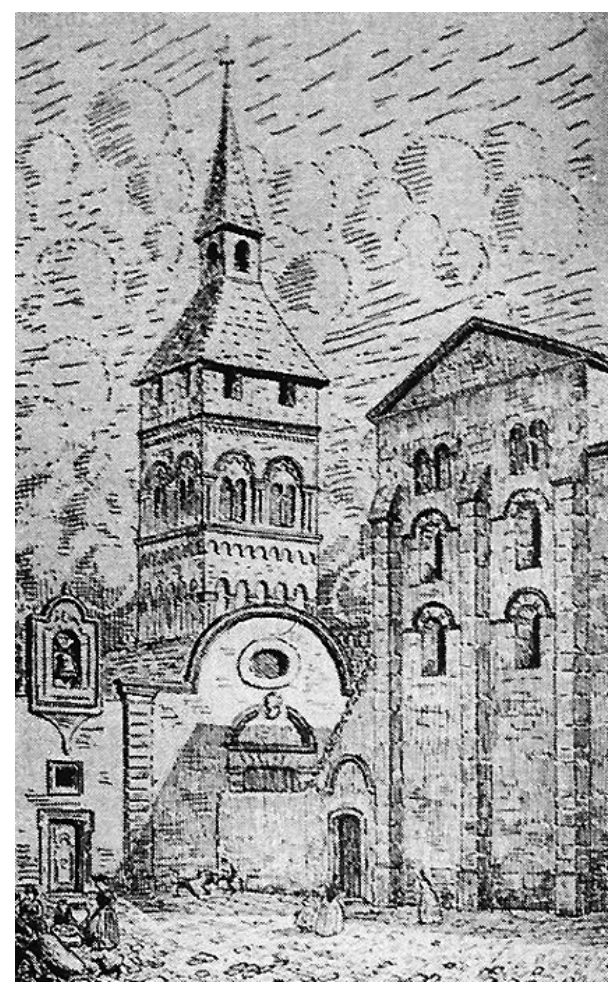

Ill. 8 : Ancien clocher de la cathédrale de Valence s'élevant au-dessus des toits de la chapelle des Pénitents (construite à l'emplacement du baptistère paléochrétien et démolie en 1860) qui s'étendait le long du bas-côté sud de la cathédrale. Vue de la place des Ormeaux vers 1800. André Blanc, La Cathédrale de Valence, témoin de l'humanité romane, Valence, éd. Peuple Libre, 1984, p. 143.

1862. En 1864, Léon Vaudoyer note: «J'ai visité le chantier de la cathédrale de Valence en août dernier : la tour était pratiquement achevée " ${ }^{26}$. L'inspecteur général trouvait que la reconstruction du clocher avait été remarquablement faite : "Cette construction est traitée avec un très grand soin [...] sous le rapport de l'art, elle décèle, de la part de son auteur, un goût très distingué et une connaissance approfondie du style qu'il a cherché à reproduire ${ }^{27}$.

Il restait à établir le beffroi pour recevoir les cloches, à reconstruire des murs de soutènement ${ }^{28}$, daller le porche de la tour et les marches d'accès et aplanir et régler

26. Arch. nat., $\mathrm{F}^{19} 7914$, affaires à soumettre à l'examen du comité des inspecteurs généraux des travaux diocésains, 12 janvier 1864.

27. Arch. nat., $\mathrm{F}^{* 19} 1823$, rapport de l'inspecteur général des édifices diocésains, Léon Vaudoyer, diocèse de Valence, cathédrale Saint-Apollinaire, 1853, p. 344-360, p. 352. Le clocher est alors au niveau du toit de la nef.

28. Les travaux de soutènement sont réalisés par l'entrepreneur François Bossu-Ragis (La $1^{\text {re }}$ soumission date du 10 octobre 1859, la deuxième, du $1^{\text {er }}$ juillet 1860). C'est encore le cas en 1867 : Arch. nat., $\mathrm{F}^{19} 7914$, lettre du préfet au ministre de la justice et des cultes, 28 février 1867. 
les terres des abords à la suite de la démolition de la chapelle des Pénitents ${ }^{29}$. Le perron et la terrasse établis autour du clocher, soutenus par un long mur en bossage furent terminés en 1869 pour la somme de 12000 francs. La hauteur totale du clocher à la base de la croix est de $45 \mathrm{~m}$. Le porche seul, en pierre de Crussol, mesure $16 \mathrm{~m}$. Les grilles en fer forgé qui ferment les trois portes du porche ont été exécutées à Paris et placées par Auguste Baudrit pour la somme de 8500 francs. Bailly fit parvenir au ministre une soumission par laquelle le sculpteur Watrinelle s'engageait à composer les modèles de la sculpture du Jugement dernier du tympan sous la forme d'un bas-relief semi-circulaire composé d'un Christ assis entouré des quatre signes évangéliques et pour le linteau, sous la forme d'un bas-relief représentant les figures assises des douze apôtres ${ }^{30}$. Le sculpteur valentinois Ferlin réalisa la sculpture décorative ${ }^{31}$.

\section{Les restaurations de Pascal}

Lorsque Pascal est nommé architecte diocésain de Valence, le 30 mars 1875, la restauration de la cathédrale a été interrompue par la guerre; il est donc confronté à des problèmes classiques d'entretien des églises : les dallages sont en mauvais état ${ }^{32}$, il faut remanier quelques parties de la couverture en tuiles creuses ${ }^{33}$, réparer les grilles en fer, les ferrures des portes et fenêtres, la charpente, le beffroi, et quelques vitraux ${ }^{34}$.

\section{La reprise des maçonneries}

En 1876, Pascal s'attaque à l'intérieur de l'édifice ; il consolide tout d'abord les voûtes de la nef: il faut reconstruire deux arcs-doubleaux de la nef principale (deuxième et troisième travée) et les voûtes adjacentes ${ }^{35}$. Pascal décide de couvrir trois travées en pierre de taille sur une charpente en fer ; la charpente est composée d'un faîtage et de pannes en fer à double $T$ qui porteront sur les murs construits sur les arcs-doubleaux. Il faut ensuite reconstruire la voûte de la tribune de l'orgue :

"La voûte n'est pas homogène ; elle a des arcs partie en ogive, partie en plein cintre dont quelques-uns sont lézardés et manquent de solidité ; c'est une

29. Ibid., rapport de l'architecte diocésain au ministre des cultes, 5 juillet 1863 .

30. Ibid., lettre du ministre de l'instruction publique et des cultes au préfet de la Drôme, 23 septembre 1862 .

31. Ibid., lettre du ministre de l'instruction publique et des cultes du préfet de la Drôme, 31 mars 1863, soumission souscrite par Ferlin pour la sculpture ornementale de la tour de la cathédrale.

32. La réparation des parties du dallage sera faite en pierre de taille de Montceau et de Saint-Marcelles-Sauzet.

33. Les tuiles seront prises parmi celles provenant de la couverture de l'évêché.

34. Arch. nat., $\mathrm{F}^{19} 7914$, devis descriptif et estimatif des travaux d'entretien à exécuter en 1876, Pascal, le 13 novembre 1875 .

35. Les arcs-doubleaux seront en pierre de taille de Châteauneuf d'Isère de $1^{\text {re }}$ qualité, de la carrière de Victor Daunonay et les voûtes, en quartiers de tuf de choix des carrières de la Sône, en Isère. Ibid., devis descriptif et estimatif des travaux d'entretien à exécuter en 1877, Pascal, 25 décembre 1876. 
addition, postérieure à la construction de l'édifice et j'aurais été tenté de la supprimer tout à fait pour rendre à la cathédrale son aspect primitif, si les besoins qui l'ont fait construire, se reproduisant actuellement, ne nécessitaient un rétablissement. Il y a plus de huit ans que l'orgue a été déposé en vue de cette reconstruction que la guerre a empêchée. Il y a donc nécessité de démolir et de reconstruire la tribune de l'orgue dans la grande nef en se rapprochant du caractère général de l'édifice et de refaire en entier le carrelage et la balustrade, après avoir préalablement placé les étais, cintres et couchis nécessaires. On utilisera autant que possible les pierres de taille provenant des démolitions pour la construction des piédroits, arcs et tympans. » 36

Pascal poursuivit ensuite la restauration des façades latérales. La façade latérale sud des deux premières travées ayant été restaurée, l'architecte restaura la façade nord de ces mêmes travées. Il établit à la partie inférieure et en parement un soubassement en pierre de taille de Crussol dans les contreforts et dans les murs des bas-côtés ainsi que cela avait été fait au sud. Au-dessus de ce soubassement, on remplaça successivement et par incrustement toutes les pierres dégradées par d'autres pierres de taille de Saint-Paul-Trois-Châteaux, de première qualité à grain fin, carrière Fabre au quartier de Sainte Juste. Le tout était posé à l'aide de mortier hydraulique. On refit également les verrières et grillages des fenêtres des deux travées. C'est l'architecte Bailly ${ }^{37}$ qui avait donné le dessin des grillages en treillis de fil de fer galvanisé qui fut placé au-dessus des verrières des deux premières travées de la façade nord. Celles-ci furent également nettoyées et remises au plomb. On plaça une verrière neuve à la fenêtre de la première travée sud. Le dallage des deux premières travées, nef et bas-côtés, fut remplacé par un carrelage en mosaïque ou en pierre de taille blanche et bleue de Saint-Marcel-lès-Sauzet, de manière à reproduire un dessin en mosaïque du XII ${ }^{\mathrm{e}}$ siècle conforme à celui exécuté autrefois dans le transept. Le devis que Pascal rédige alors pour la réfection de l'intérieur de l'église est très respectueux de l'édifice original, de ses matériaux, et des techniques de construction anciennes. Le comité des inspecteurs généraux n'en jugera pas ainsi ; en 1879, Pascal décide d'enlever le badigeon et les peintures modernes "de mauvais goût ", et de procéder à la réfection des enduits en mortier sur les murs et les voûtains ${ }^{38}$. Il est alors désavoué par le comité des inspecteurs généraux :

«Le comité regrette que les travaux, qui font l'objet du devis complémentaire présenté, aient reçu même un commencement d'exécution, car il les désapprouve absolument. La restauration intérieure, telle qu'on l'a entendue, constitue, selon le comité, une sorte de rhabillage superficiel, sans garantie de durée et de nature à modifier l'aspect du monument, dont le caractère

36. Ibid.

37. Ibid., devis descriptif et estimatif des travaux d'entretien à exécuter en 1875, Bailly, 30 novembre 1874.

38. Arch. nat., $\mathrm{F}^{19} 7914$, affaires à soumettre à l'examen du comité des inspecteurs généraux des travaux diocésains, grosses réparations, 1879. 
réside surtout dans l'allure brutale de ses surfaces rugueuses. En conséquence, le comité émet l'avis qu'il y aurait lieu de repousser la proposition de l'architecte, en l'invitant à se contenter de réparer les parties frustes ou mauvaises des façades par les procédés ordinaires, c'est-à-dire par relancis et jointoiements. » ${ }^{39}$

L'architecte, à qui l'on reprochait d'avoir employé du ciment métallique, expliqua sa conception de la restauration du monument :

"Chaque fois qu'il y a moyen de rétablir sûrement ce qui a pu exister primitivement, j'ai tenu la main et je continuerai à exiger qu'on remplace les anciens matériaux abîmés par des matériaux de forme et de nature semblables à ceux qu'on déposera. Mais lorsque des parements sont dégradés, constitués de matériaux hétérogènes, sans possibilité de raccordement des hauteurs d'assises, lorsqu'il s'agit des surfaces seulement, il m'a paru plus économique et plus logique de ne point entamer les murailles dans la moitié de leur épaisseur et de me contenter d'un arrangement avec du ciment métallique qui m’a donné sur différents points de bons résultats et une similitude très grande avec des parties voisines ${ }^{40}$.

Le comité des inspecteurs généraux va exiger de Pascal que ses restaurations soient " lisibles ":

"Le comité a pensé qu'il conviendrait de substituer aux enduits en ciment métallique des reprises en matériaux de même nature que ceux de la construction primitive de la cathédrale en ayant soin de conserver toutes les parties anciennes dont le remplacement n'intéresserait pas essentiellement la solidité de l'édifice. Le comité ajoute que vous ne devez pas chercher à donner un aspect uniforme à l'ensemble du monument mais au contraire bien laisser voir la distinction qui se produira entre les parties restaurées et les parties primitives afin qu'il soit établi que son caractère est resté le même " ${ }^{41}$.

Pascal rédige alors un devis proposant une véritable restauration "à l'identique ", telle que l'on peut la concevoir de nos jours. Est-ce cette passe d'armes avec le comité des inspecteurs généraux qui entraîna l'ordre de suspendre en avril 1881 tout travail dans les édifices diocésains dont il avait la charge? :

"Au moment où nous finissions le ragrément intérieur de l'édifice pour passer à une restauration extérieure bien urgente, un ordre de suspendre les travaux me fut adressé et je m'y conforme depuis plus de deux ans, n'ayant strictement achevé que ce qui était indispensable pour ne pas compromettre l'exercice du culte et la sécurité des fidèles. [...] Vingt-deux mois après sur-

39. Ibid., extrait du registre des délibérations du comité des inspecteurs généraux des édifices diocésains, séance du 14 juin 1880 .

40. Ibid., rapport de l'architecte diocésain sur les dépenses à faire en 1880, adressé au ministre par Pascal, 18 juin 1880.

41. Ibid., minute du 7 août 1880 , ministère de l'instruction publique et des cultes. 
vint un évènement tout à fait imprévu : un énergumène mit le feu dans la cathédrale et y causa d'importants dégâts " ${ }^{42}$.

Émile Lioret, entrepreneur en maçonnerie et charpente fut chargé de restaurer les maçonneries altérées ou en partie détruites par l'incendie du 7 mars $1882^{43}$. Les instructions de Pascal étaient précises :

«L'appareil des pierres neuves sera absolument semblable à l'appareil ancien. Les arcs seront extradossés, les parements faits en assises de même hauteur que les anciennes. La taille des pierres sera faite au taillant droit et conforme à celle de la construction primitive de l'église. L'emploi de plâtre, de mastic ou de ciment quelconque est rigoureusement interdit, de même que celui de la boucharde pour la taille et de crampons en fer pour relier les pierres. ${ }^{44}$

En 1890, Pascal décida de refaire, en pierre de Chateauneuf d'Isère, quelques parties de soubassement des murs de l'abside qui tombaient en ruine. Une grille en fer, due à Ernest Collot ${ }^{45}$, serrurier mécanicien à Valence, courant sur la longueur de l'abside restaurée, vint la protéger des dégradations. Au-dessus de la porte septentrionale de la cathédrale, il y avait un petit clocher dont le pilier sud-ouest de plan rectangulaire était rongé (ill. 4) ; le clocher était couvert d'un comble à quatre pentes en tuiles qui était à reprendre. La partie basse en était ancienne, mais à partir de la corniche du transept, contre lequel il était accolé, les matériaux qui le composaient dataient du début du XIX ${ }^{\mathrm{e}}$ siècle.

On se servait en effet au Moyen Âge, à l'intérieur du cloître situé au nord de l'église, de clochettes pour réveiller les clercs aux heures des offices et on avait construit, sur la porte qui allait du cloître à l'église, un clocheton où Guillaume, frère de l'évêque Jean de Poitiers (évêque de Valence de 1390 à 1447), avait fait placer une cloche de petite taille. Pascal en proposa la démolition ${ }^{46}$; le directeur des cultes lui écrivit : "Vous proposez la démolition d'un clocher sans valeur architecturale construit sur la façade nord de la cathédrale, au-dessus du porche relié autrefois avec le cloître et dont l'état de vétusté exigerait d'importantes réparations.

42. Arch. nat., $\mathrm{F}^{19}$ 7914, rapport de l'architecte diocésain Pascal au directeur des cultes, 29 janvier 1883.

43. L'incendie avait été allumé dans l'entrepôt de chaises situé dans la $1^{\text {re }}$ travée du bas-côté nord par un certain Dijoud, sorti le 20 février 1882 de la maison d'arrêt de Valence. Trois vitraux ont été complètement brisés ; les cinq cents chaises ont brûlé ainsi que quelques placards et boiseries; la $1^{\text {re }}$ travée du bas-côté nord près de l'entrée principale a été gravement endommagée ; la voûte, les colonnes et les revêtements des murs construits en blocs de pierre de taille appareillés ont reçu l'atteinte du feu, plusieurs blocs se sont fendus, les moulures et les sculptures ont été écornées et brisées. L'entrée principale et la tribune contiguë ont beaucoup souffert; une partie des nervures de la voûte a été détériorée. La seconde fenêtre latérale au nord devait être entièrement reconstruite. Arch. nat., $\mathrm{F}^{19}$ 7914, lettre de Pascal au ministre des cultes, 16 mars 1882.

44. Ibid., devis de Pascal du 26 janvier 1883.

45. Arch. nat., $\mathrm{F}^{19} 7915$, soumission du $1^{\text {er }}$ septembre 1896. Ernest Collot habite 12 rue Notre-Dame à Valence. Il réalise la grille pour 2543,35 francs.

46. Ibid., lettre de Pascal au directeur des cultes, 7 septembre 1898. 


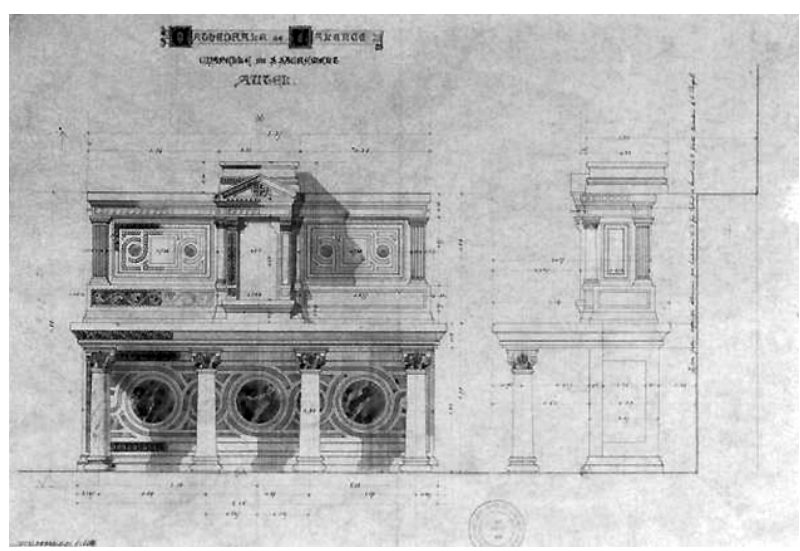

Ill. 9 : Projet d'autel pour la chapelle du Saint-Sacrement de la cathédrale de Valence. Jean-Louis Pascal. B.n.F., dp. Est., Ha 132.

Le comité des travaux diocésains consulté à ce sujet a émis en principe un avis favorable à cette proposition; toutefois, il croit devoir appeler votre attention sur la partie basse qui parait ancienne ${ }^{47}$. En 1905, Pascal entreprit la restauration de la façade du collatéral nord, de celle du transept surmontant le porche nord et la reconstruction du clocheton.

Il restaura de plus le vieux porche du XVIII ${ }^{e}$ siècle, dans lequel était engagée la porte latérale du transept de l'église primitive (ill. 4).

\section{La chapelle du Saint-Sacrement}

C'était l'ancienne chapelle de Notre-Dame-du-Saint-Rosaire (absidiole du transept nord). En 1888, Pascal réaménagea cette chapelle grâce à la libéralité des fidèles, en témoignage d'une dévotion particulière. À la suite du devis ${ }^{48}$ proposant les travaux nécessaires à l'assainissement de cette chapelle, l'installation d'appareils à gaz et de conduites pour l'éclairage du transept ainsi que divers travaux de restauration dans la cathédrale, Pascal se vit demander par le ministère de s'en tenir à une stricte conservation du monument: «Il ne s'agit pas aujourd'hui de reprendre le projet de votre prédécesseur qui entraînerait des dépenses beaucoup trop considérables et qui en outre aurait l'inconvénient de dénaturer complètement cet édifice. Il importe en effet de lui conserver son aspect général actuel en se bornant à réparer les injures du temps. ${ }^{49}$

47. Ibid., lettre du directeur des cultes Dumay à Pascal, 22 octobre 1898.

48. Arch. nat., $\mathrm{F}^{19}$ 7915. Ministère de la justice et des cultes. Affaires à soumettre à l'examen du comité des inspecteurs généraux des travaux diocésains. Département de la Drôme, diocèse de Valence, grosses réparations, 1887 .

49. Ibid., lettre du directeur des cultes à Pascal, 14 mai 1887. 


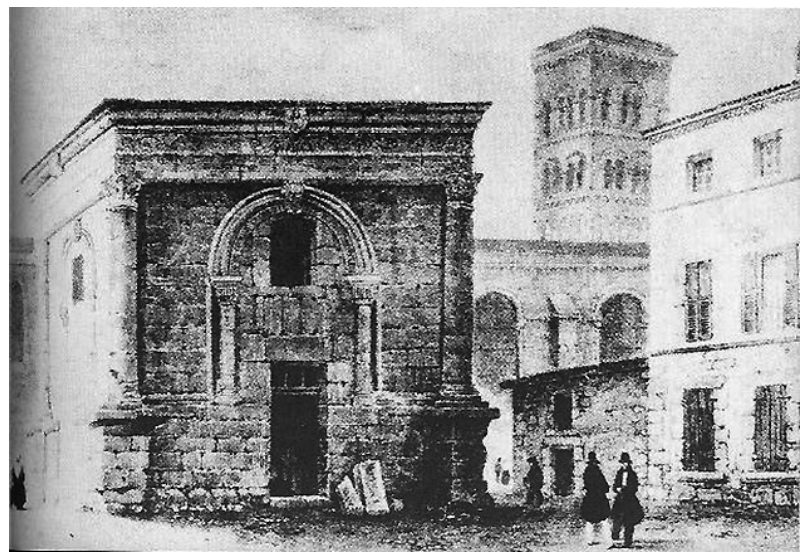

Ill. 10 : Le Pendentif situé sur le parvis nord de la cathédrale de Valence, vers 1830, avant son rachat par la ville et sa restauration. C'était à l'origine une chapelle funéraire dédiée à la Vierge, construite en 1548 par le chanoine Nicolas Mistral. André Blanc, La Cathédrale de Valence, témoin de l'humanité romane, Valence, éd. Peuple Libre, 1984, p. 161.

Pascal proposa de refaire le dallage de la chapelle ${ }^{50}$ et d'orner la base des murs entourant l'autel d'un revêtement en marqueterie de marbres polis. Il réalisa l'appui de communion en pierre d'Échaillon, l'autel en marbre blanc d'Italie avec crédence, colonnes et incrustations en marbre de couleur et panneaux en mosaïque d'émail sur fond d'or, le tabernacle en bois avec porte de bronze (ill. 9). Tout ceci fut jugé beaucoup trop opulent par le directeur des cultes : «Si en plaçant l'autel, [...] vous avez cru pouvoir commencer ce travail [les revêtements en marbre], je vous prie d'enlever immédiatement cette décoration qui ne saurait être autorisée ni conservée. " 51

Pascal répondit : "Le travail n'est plus à faire : il est terminé depuis quinze jours. Et j'argue de ma bonne foi à ce sujet " ${ }^{52}$. Le directeur des cultes écrivit à Émile Vaudremer, inspecteur général des travaux diocésains :

"Je crois devoir appeler votre attention sur les placages en marbre et sur l'appui de communion, en pierre d'Échaillon, avec saillie sur le transept et exécuté sans autorisation. Lors de l'examen du projet de décoration de cette chapelle, le comité des travaux diocésains avait fait remarquer que ces revêtements en marbre modifieraient l'aspect sévère de la cathédrale et qu'il n'y

50. Le devis de Pascal propose « divers travaux nécessaires pour l'assainissement de la chapelle absidale du transept nord; ces travaux consisteraient dans l'application de deux couches d'asphalte sur le sol préalablement recouvert d'un béton de 0,20 m d'épaisseur et la réfection du dallage avec repose d'une partie des vieilles dalles sous l'autel et substitution d'une mosaïque en marbre au vieux dallage pour le surplus. " (Le tout pour 1 210,98 francs). Ibid., ministère de la justice et des cultes. Affaires à soumettre à l'examen du comité des inspecteurs généraux des travaux diocésains. Département de la Drôme, diocèse de Valence, grosses réparations, 1887.

51. Arch. nat., $F^{19} 7914$, lettre du directeur des cultes Dumay à Pascal, 24 juin 1887.

52. Ibid., lettre de Pascal au directeur des cultes Dumay, 25 juin 1887. 
avait pas lieu d'en autoriser l'exécution. Quant à l'appui de communion, le comité avait fait remarquer que l'emploi de la pierre obligeait de lui donner une importance exagérée et que le dessin produit ne répondait pas au caractère de l'édifice ; il ajoutait qu'il était préférable d'établir une simple grille en fer $»^{53}$.

En 1891, le directeur des cultes, sur avis du comité des travaux diocésains, demandait à Pascal que l'appui de communion fût remplacé par une grille en fer et que celle-ci soit placée en arrière, entre les deux têtes des murs, de manière à conserver les colonnes complètement dégagées ${ }^{54}$. Ce ne fut pas la seule passe d'armes entre Dumay et Pascal ; en 1900, à la mort de l'abbé Didelot, qui avait tant ouvré pour l'embellissement de la cathédrale, le directeur des cultes demanda à Pascal de lui élever un monument. Pascal proposa un texte à graver sur une plaque de marbre appliquée à l'entrée de la chapelle du Saint-Sacrement, embellie grâce aux libéralités de l'abbé, sur le mur est du bras nord du transept. De part et d'autre de la plaque, deux consoles supportaient des colonnettes et un fronton s'arrondissait au-dessus d'un médaillon de bronze à l'effigie du chanoine Didelot ${ }^{55}$. Le texte proposé par Pascal était celui-ci : "À la mémoire vénérée de Charles Joseph Didelot, né à Valence le 9 avril 1826, curé fondateur de la paroisse Notre-Dame, 1858-1868. Archiprêtre de la cathédrale, 8 mai 1868-20 janvier 1900. Bienfaiteur insigne de cette basilique Saint-Apollinaire. "

Un avis du ministère des cultes lui interdit de mettre les termes "archiprêtre » et "basilique " et lui demanda d'y substituer les termes de "curé " et de "cathédrale » et une lettre du directeur des cultes lui reprocha l'importance de l'édicule et son emplacement. Pascal rappela tous les dons que le chanoine avait fait pour embellir l'église : "Tout cela vaut bien le rapport plus ou moins formaliste qu'en principe il convient d'établir entre un évêque et un curé dans une cathédrale, d'autant plus que dans Saint-Apollinaire il n'y a point de tombeau d'évêque. " ${ }^{56}$ Tout cela cachait une rancœur à son égard, et Pascal, qui n'était pas dupe, le fit savoir au directeur des cultes et maintint le monument tel qu'il l'avait décidé :

"Je mets une lettre [...] pour vous demander si les objections qu'on a faites à mon modeste tombeau du curé de Valence ne visent pas plutôt, - comme il est déjà arrivé -, mon goût personnel, une tournure d'art qui ne plaît pas, que les raisons officielles énumérées dans la lettre suspensive qui m’a causé quelque chagrin. L'église est cathédrale ; mais je sais aussi qu'elle est paroissiale, et je n'aurais que l'embarras du choix pour citer des plaques commé-

53. Ibid., lettre du directeur des cultes Dumay à Émile Vaudremer, inspecteur général des travaux diocésains, mars 1888.

54. Arch. nat., $\mathrm{F}^{19} 7915$, lettre du directeur des cultes à Pascal, 30 novembre 1891.

55. Il semble que Pascal ait tout à fait repris le schéma du monument au colonel d'Argy, qu'il avait réalisé trente ans auparavant à Saint-Louis-des-Français à Rome, mais dans une version plus décorative.

56. Arch. nat., $\mathrm{F}^{19}$ 7915, lettre de Pascal au ministre, 29 mai 1901. 
moratives de curés plus importantes que celle dont il s'agit. Cette objection tombe donc. [...] Ici, j’ai pris le médaillon qu'on avait, et, vraiment à comparer avec d'autres édicules dont j'ai eu l'honneur d'être chargé, je crois l'avoir encadré sans grande prétention. L'archiprêtre était presque un ami personnel de M. le Président de la République; je me permets de vous signaler qu’il ne serait guère utile de donner à ce petit conflit inattendu de l'importance et je crois pouvoir vous demander de me laisser mettre sans autre difficulté cette œuvre que j'ai soignée, - telle quelle, pas comme quelque chose dont on ait honte - mais à une place qui n'a d'autre prétention que de lui faire recevoir un peu de lumière " 57 .

\section{Les vitraux}

L'incendie qui s'était déroulé le 7 mars 1882 avait détruit certaines verrières en grisailles avec verres de couleur et la plupart des tableaux de l'église qui avait été entreposés dans la tribune de l'orgue pendant les restaurations. Pascal proposa de remplacer les grisailles par des panneaux identiques; on choisit l'entrepreneur de vitraux d'église, Thomas Pierre ${ }^{58}$; il devait employer des verres anglais ou équivalents. On remplaça en 1883 les vitraux détruits par l'incendie, mais les autres, quoique restés debout et paraissant intacts, avaient été altérés par la chaleur. Peu de temps après, les vents violents, en les ébranlant, achevèrent d'en compromettre la solidité peu assurée dès l'origine par des armatures en fer trop faibles et mal disposées. Pascal demanda de changer d'entrepreneur ; les nouveaux vitraux plongeaient l'édifice dans une semi-obscurité par leur coloration excessive :

«Dans le but louable de favoriser une industrie locale, les vitraux furent confiés à un verrier de Valence ; mais le résultat ne donna pas toute satisfaction. Il ne trouvait pas les verres qu’il fallait; le dessin géométrique était entremêlé de rinceaux dont il ne conserva pas parfaitement le caractère ; la coloration enfin ne fut pas aussi harmonieuse qu'on l'aurait souhaité [...] L'industriel favorisé n'a d'ailleurs pas réussi à Valence et cette considération d'un arrangement local n'aurait plus de raison d'être. On pourrait donc s'adresser à de bonnes et sérieuses maisons pour obtenir un résultat digne de l'édifice. " 59

Pour remplacer, grâce aux 1200 francs d'un généreux donateur, le vitrail bleu losangé de la chapelle du bras nord du transept dégagé en 1891, appelée chapelle du Saint-Sacrement, Pascal proposa une esquisse de vitrail à figure, entourée d'un motif architectural ; il lui fut répondu : «Le comité [...] croit devoir appeler votre attention à l'avantage qu'il y aurait peut-être à dégager la figure soit en supprimant l'architecture et en la remplaçant par une simple bordure soit en cherchant à en diminuer l'importance ${ }^{60}$. Pascal maintint sa proposition :

57. Ibid., lettre de Pascal au directeur des cultes, 29 mai 1901.

58. Les travaux sont évalués à 2616 francs. Arch. nat., $F^{19} 7914$, soumission du 9 avril 1883.

59. Arch. nat., $\mathrm{F}^{19} 7915$, lettre de Pascal au directeur des cultes, 7 juillet 1890.

60. Ibid., lettre du directeur des cultes Dumay à Pascal, 24 novembre 1891. 
"L'architecture ne sera qu'un jeu de fond ton sur ton et ne comptera que dans une coloration générale uniforme. C'est donc un simple motif de mise au plomb et la figure n'en sera pas engorgée comme s'il s'était agi de tons variés : la bordure seule sera franchement colorée. Quant à en diminuer l'importance, le dessin d'ensemble ne permettrait pas à mon avis de réduire la dimension de la figure. " ${ }^{61}$

Le carton de la verrière à l'image du bon pasteur fut réalisé d'après un carton du peintre valentinois Lagrand, grand prix de Rome, par le peintre-verrier parisien G. Bardon" ${ }^{62}$ : "J'ai donc arrêté mon choix à la maison Bardon de qui je connais des vitraux remarquables sur des dessins de Jean-Paul Laurens, de Joseph Blanc ${ }^{63}$. Grâce aux libéralités du chanoine Didelot et à son action (il avait obtenu des Chartreux de Grenoble la promesse formelle de pourvoir jusqu'à concurrence de 14000 francs aux dépenses prévues au devis de restauration), Pascal put refaire les verrières des collatéraux (onze fenêtres ${ }^{64}$ ) et des transepts (douze fenêtres ${ }^{65}$ ) : "Mon intention, en laissant subsister le parti de grisaille qui fait le fond de la composition et semble nécessaire pour l'éclairage de l'église, est de varier les dessins à chaque verrière ou tout du moins, de deux en deux, en maintenant toujours des dispositions géométriques ou des ornements de répétition " ${ }^{66}$. Une fenêtre nouvelle s'ouvrit dans la travée du collatéral nord sous la tribune, où devaient être placés les fonts baptismaux.

\section{Les orgues}

Pour établir les fondations du nouveau clocher, le pignon occidental de l'église avait été dégarni ; la façade avait subi un mouvement et la solidité de la voûte était compromise dans sa partie antérieure. En 1870, pour reconstruire les travées du fond de la nef, on démonta les grandes orgues de la cathédrale dont toutes les pièces furent entreposées à l'évêché. Sa mécanique périt dans ce démontage. Cet orgue datant de 1768 avait été commandé à François-Henri Clicquot (1732-1790) pour remplacer l'orgue précédent qui datait $\mathrm{du} \mathrm{XIV}^{\mathrm{e}}$ siècle $^{67}$. Il possédait quarante-trois jeux contenus dans un buffet à deux corps, le positif et le grand orgue. À l'époque, on avait ouvert une fenêtre latérale pour donner plus de lumière à la tribune, on

61. Ibid., lettre de Pascal au directeur des cultes Dumay, 5 décembre 1891.

62. Ibid., lettre de Pascal au directeur des cultes, 31 août 1891. Bardon habite 21 rue Victor Massé à Paris.

63. Ibid., lettre de Pascal au directeur des cultes, 28 avril 1891.

64. Elles mesurent : 3,89 $\mathrm{m} \times 1,61 \mathrm{~m}$. Ibid., devis de Pascal du $1^{\text {er }}$ décembre 1890 .

65. Elles mesurent : 1,94 m $\times 0,93 \mathrm{~m}$. Ibid., devis de Pascal du $1^{\text {er }}$ décembre 1890 .

66. Arch. nat., $\mathrm{F}^{19} 7915$, lettre de Pascal au directeur des cultes, 19 mars 1891.

67. Arch. nat., $\mathrm{F}^{19} 7915$, lettre de l'évêque Charles au préfet de la Drôme, 14 janvier 1898 . Le chanoine Perrot l'attribue, lui, au maître-facteur Scherer et évoque un marché conclu avec lui et son fils le 29 novembre 1751 ; chanoine J. Perrot, La Basilique de Saint-Apollinaire, op. cit., p. 187. Léon Vaudoyer, inspecteur général des édifices diocésains le date de 1755 ; Arch. nat., F*19 1823 , rapport de l'inspecteur général des édifices diocésains, Léon Vaudoyer, diocèse de valence, cathédrale Saint-Apollinaire, 1853, p. 344-360. 
avait établi une barrière en fer et on avait fait sculpter un grand cartouche représentant deux anges soutenant les armoiries du donateur, Alexandre Milon.

En 1875, lorsque Pascal est nommé à Valence, il demande à rétablir le grand orgue démonté à l'époque de la construction du clocher :

«Par ma lettre du 13 novembre 1875, je réitérais une demande plusieurs fois présentée par mon prédécesseur, pour obtenir la restauration des deux premières travées de la cathédrale voisines du clocher neuf et dont les voûtes sont déformées. Le travail comprenait la restauration de la partie de l'église qui abrite la tribune sur laquelle Monseigneur voudrait faire rétablir les orgues déposées et inutiles depuis plusieurs années. [...] Je n'ai pu obtenir, en tout, sur l'exercice 1876, qu'une somme de 12000 francs pour l'entretien d'un édifice très ancien, très curieux et très abîmé " ${ }^{68}$.

L'évêque de Valence, Mgr Charles ${ }^{69}$ (1825-1905) proposa de verser 2000 francs pour contribuer aux dépenses. Pascal réitéra en 1881 :

"Le vieux buffet d'orgue, déposé depuis 1870, [...] s'abîme tous les jours de plus en plus, [...] L'instrument est du siècle dernier; il n'est donc pas en harmonie avec le style général de l'édifice roman très primitif, mais je n'estime pas qu'il convienne de proposer la confection d'un nouveau buffet, si l'état d'abandon des boiseries depuis dix ans permet encore de les utiliser, ce qui est l'avis de M. Merklin, le facteur qui a déposé le vieil orgue. " ${ }^{70}$

En 1899, Pascal s'attaque à la reconstitution des boiseries sculptées qui couvraient la tribune de l'orgue et que l'on avait descendues lors de la reconstruction du clocher ; il fallait reconstituer un des deux anges, disparu, qui tenaient le cartouche de Mgr Milon, et toute une décoration florale décorant la tribune. Pascal s'adressa tout d'abord à l'ébéniste Germain Faure qui avait jadis beaucoup travaillé avec Viollet-le-Duc :

«La reconstitution des boiseries sculptées qui avaient été - avant la guerre descendues de la tribune de la cathédrale de Valence, a demandé une reconstitution que je qualifierai d'artistique pour laquelle la compétence de M. Germain Faure, praticien habile, mais insuffisant pour la composition et l'arrangement, ne répondait pas complètement à ma direction non plus qu'à

68. Arch. nat., $\mathrm{F}^{19}$ 7914, rapport de l'architecte diocésain sur les dépenses à faire en 1876, 26 septembre 1876 ,

69. Charles Pierre François Cotton, né à Saint-Siméon-de-Bressieux (Isère), curé-archiprêtre de la cathédrale de Grenoble, fut nommé évêque de Valence par décret du 16 janvier 1875. Ardent défenseur des droits de l'Église, il protesta avec énergie contre les décrets qui atteignaient les religieux. Il créa la Semaine Religieuse (1890). Il repose sous le maitre-autel de la cathédrale. Chanoine J. Perrot, La Basilique de Saint-Apollinaire, op. cit., p. 344.

70. Arch. nat., $\mathrm{F}^{19}$ 7914, lettre de Pascal au directeur des cultes Rozan, 15 janvier 1881. 
celle de mon inspecteur M. Romiguière ${ }^{71}$. Sur les deux anges, nous n'en avions qu'un entier; de l'autre il ne restait que les deux ailes et une main. Il ne pouvait être question de confier à notre ébéniste sculpteur la composition de cette figure dont le caractère décoratif, très largement et quelquefois grossièrement traité devait correspondre à la physionomie quelque peu archéologique, très souple, et d'une valeur très juste pour sa place, qu'offrait l'ange encore intact. J'en confiai [pour 800 francs] la maquette à un jeune sculpteur, élève de l'École des beaux-arts, M. Duquesne, frère de l'architecte pensionnaire de Rome. " ${ }^{72}$

Germain Faure essaya longuement et inutilement de réunir les fragments de palmes, de fleurs, de feuillages, réduits en miettes, qui accompagnaient les anges, en une combinaison qui pût être considérée comme la reproduction de ce qui existait autrefois. Devant ses hésitations, Pascal fit venir les morceaux à Paris et recomposa un motif, ne reproduisant peut-être pas l'ancien, mais s'en approchant beaucoup :

"Il me fallait un sculpteur pour réaliser les croquis proposés, pour compléter les parties manquantes entre les palmes ou ornements qui paraissaient se suivre, pour établir les saillies, les reliefs, les formes des fleurs dont on voyait la trace par un collage, par une découpure, par un coup d'outil. M. Duquesne, jeune, désireux de donner satisfaction, curieux de cette besogne de reconstitution, y donna beaucoup de temps [...] Ce jeu de patience laissait à M. Faure une exécution fort difficile ; il préféra en abandonner les parties les plus détériorées et les reproduire en bois neuf, ce qui assurait à l'ensemble une solidité nécessaire ${ }^{73}$.

Pascal réalisa pour cet orgue un travail remarquable de restitution :

" Je me suis acharné sur le buffet et sur le positif; des relevés précis m’ont été fournis; je me suis fait envoyer à Paris des morceaux nombreux de sculpture pour étudier ce que la disposition des clous de fixation, les trous des collages, l'agencement des pièces entre elles pouvaient suggérer pour la reconstitution des ensembles. M. Romiguière, mon inspecteur, m'a secondé avec beaucoup de méthode et de d'attention, aidant le représentant de M. Cavaillé-Coll, contrôlant ou repoussant mes hypothèses, s'assurant des réalités, n'acceptant que les certitudes. On a étendu dans la grande salle à manger de l'évêché, actuellement inutilisé par suite de l'état de santé de Mgr Cotton, tous les fragments. On a descendu des vases à fleurs en bois ayant servi à décorer temporairement des chapelles; un grand ange en bois aussi, de 1,62 $\mathrm{m}$ de hauteur, et aussi quatre ailes, dont deux adaptant exactement leurs tenons aux mortaises des omoplates de la statue. L'autre figure a disparu. On croit savoir qu'elle était vermoulue et n'avait pu être conservée. Je n'en ai nulle

71. Édouard Melchior Romiguière est nommé inspecteur des travaux diocésains de Valence le 20 novembre 1889.

72. Arch. nat., $\mathrm{F}^{19} 7915$, lettre de Pascal au ministre, 24 octobre 1899.

73. Ibid. 
preuve, mais jusqu'ici comme on a rien trouvé, il faut penser à en reconstituer une autre. La place des deux anges est bien assurée maintenant. J'en suis plus content que de l'emploi des morceaux de palmes et d'ornements qui sont accrochées à celles-ci et dont l'adaptation peut prêter à plusieurs arrangements. Le dessin que j'ai l'honneur de soumettre à l'approbation du comité des inspecteurs diocésains présente cependant grand'chance de probabilité ${ }^{74}$.

Charles Mutin, entrepreneur de menuiserie, reconstitua sur la tribune, les charpentes, menuiseries, panneaux d'ébénisterie et boiseries sculptées, tous travaux d'ébénisterie spéciale, en vue de la réinstallation des grandes orgues ${ }^{75}$. En 1898, le chanoine Charles-Joseph Didelot avait proposé de partager avec l'État les frais d'un nouvel orgue; il fut fourni par la maison Cavaillé-Coll de Paris. Il comprenait trente-cinq jeux, trois claviers et un pédalier ${ }^{76}$.

\section{L'aménagement des abords de la cathédrale}

La démolition en 1891 de la maison Milhan située sur la place des Clercs (ill. 5 et 6), acquise par l'État depuis $1881^{77}$, dégagea le chevet et la partie nord du transept regardant le levant. Cela dégagea deux fenêtres, l'une dans le déambulatoire, l'autre dans la chapelle semi-circulaire de ce même bras nord contenant la chapelle du Saint-Sacrement.

\section{Le parvis sud}

La ville de Valence désirant dégager l'espace au sud de la cathédrale, ouvrir un passage au public entre cette dernière et l'évêché ${ }^{78}$ et rétablir une communication entre la haute et la basse ville, mit 6000 francs à la disposition de Pascal ; au midi, la chapelle Saint-Étienne s'étendait jusque dans les années 1860 contre la paroi extérieure du collatéral, presque jusqu'au transept, dont elle n'était séparée que par l'épaisseur du tambour et par une masure servant de débarras à l'église, qui existe encore en 1891 (ill. 8) ; à l'époque, l'encerclement était si complet, qu'on pouvait se demander comment, en dehors de la côte Saint-Estève, on accédait au porche de l'ancien clocher. À l'issue de la démolition de la chapelle, en 1866, on nivela et on abaissa le terrain entre la cathédrale et l'évêché, ce qui permit de mettre à jour une partie du baptistère paléochrétien.

74. Ibid., lettre de Pascal au ministre, 31 octobre 1897.

75. Soumission du 4 juillet 1899, ibid., lettre du préfet de la Drôme au ministre de l'instruction publique et des cultes, 10 juillet 1899. Charles Mutin habite 15 avenue du Maine à Paris.

76. Chanoine J. Perrot, La Basilique de Saint-Apollinaire, op. cit., p. 258.

77. La maison était toutefois grevée d'une servitude d'usufruit.

78. C'est un vaste hôtel particulier du XVIII ${ }^{\mathrm{e}}$ siècle situé au $\mathrm{n}^{\mathrm{o}} 4$ de la place des Ormeaux, au flanc sud de la cathédrale. 
Pascal présenta au directeur des cultes un projet d'aménagement du site, avec mise en valeur des restes antiques, tel qu'on peut en voir de nos jours :

"La conséquence de cette opération est la démolition de sales baraques adossées à la façade sud de l'église, baraques contenant des objets pour les cérémonies funèbres, du charbon pour le calorifere et le calorifere provisoire qu'on y a installé il y a quelques années. [...] Une grille fermée le soir, avec guichet de piétons et porte à deux vantaux devrait être établie à la place de notre clôture en planches. On disposerait des candélabres et des bancs pour permettre au public de jouir de la magnifique vue [sur le Rhône] qu'on a de cette plateforme. Enfin il y aurait lieu de rappeler le souvenir du baptistère primitif dont les fondations et des parties de mosaïque existent encore sur cet emplacement. On ne pourrait penser à les faire sortir de leur long enfouissement, car elles disparaissent rapidement, mais il serait sans doute possible de tracer en pavés ou dalles de couleur les contours du plan, et peut-être de sortir quelques fragments de mosaïque pour en faire une façon d'exposition en quelque lieu bien choisi. " ${ }^{79}$

Pascal indique de plus que le vieux porche (côté sud) enferme une belle porte romane sculptée qu'il faudrait mettre à jour ; à la place des bicoques qui l'accompagnent, l'architecte propose de lui adosser une petite construction dans le caractère du monument, devant contenir un escalier d'accès, une soute à charbon et l'instrument de chauffage destiné à remplacer le calorifere provisoire. La place des Clercs, au chevet de la cathédrale, serait nivelée et abaissée; les soubassements seraient régularisés ainsi que le seuil du porche qui oblige à descendre des marches pour rentrer dans l'église. Dans l'espace voisin de la cathédrale, un trottoir, des bancs, des réverbères, une chaussée seraient organisés, enfin une grille disposée en pans coupés séparerait le domaine de l'État, du terrain de la ville, remplaçant une vieille palissade.

En 1902, Pascal propose la reconstruction du porche sud, utilisant en élévation la pierre dure de Chomérac ${ }^{80}$ et celle de Chamaret $^{81}$ (carrière de Rochetaillée) ; pour la petite construction contenant le calorifere, Pascal construit un escalier menant

79. Arch. nat., $\mathrm{F}^{19}$ 7915, lettre de Pascal au directeur des cultes, 31 août 1891. Les entrepreneurs choisis pour aménager les abords seront : Paul Bac, entrepreneur général de plomberie et distribution d'eau, 1 rue Notre-Dame de la Ronde à Valence (soumission du 21 juin 1901), Prosper Ducol, pour la maçonnerie et Fuzier-Francon pour la serrurerie, 10 rue des Balais à Valence (note du contrôle, ministère de la justice et des cultes, 21 juillet 1899). Les candélabres sont en fonte, modèle Durenne, de 2,97 m au-dessus du sol. Sur les montants du portail, des lanternes rondes ou à pans, en cuivre fondu, modèle de la ville de Valence, fabrication de Dériard de Lyon, avec fumivore surmonté d'une croix, diamètre de la lanterne: 0,50 m, hauteur: 0,80 m. Ibid., devis relatif à l'installation de conduites et d'appareils pour l'éclairage au gaz de l'espace compris entre la cathédrale et l'évêché établi par Pascal (1 889,97 francs), $1^{\text {er }}$ juin 1901.

80. La pierre de Chomérac, du nom d'un village de l'Ardèche dans la vallée de la Payre, est célèbre dans toute l'Europe pour ses qualités : c'est une pierre non gélive et particulièrement adaptée aux encadrements et aux monuments.

81. Chamaret se trouve dans le canton de Grignan, arrondissement de Nyons, dans la Drôme. 
au sous-sol en pierre de Puygiron ${ }^{82}$, le plancher haut du sous-sol en fer, les voûtes en briques creuses et mortier de ciment. Le dallage du sous-sol et du trottoir est réalisé en béton de ciment du Valbonnais ${ }^{83}$, celui du porche et de l'annexe, en pierre de Puygiron. Les bordures de trottoir sont réalisées en pierre de Crussol. Les portes du porche ainsi que les menuiseries pour le tambour d'entrée sont refaites en chêne ${ }^{84}$. On restaure le bas-relief du tympan ${ }^{85}$ de la porte d'entrée du porche, les chapiteaux des colonnettes formant contreforts ainsi que ceux des colonnettes situées à la porte d'entrée du porche et à l'ancienne porte restaurée ${ }^{86}$.

\section{Le parvis nord}

En 1903, une somme de 2500 francs est attribuée à Pascal par la municipalité pour réapproprier le parvis nord de la cathédrale. Le cloître moyenâgeux avait été détruit en 1567 ; il ne subsistait en son centre qu'un édicule de la Renaissance appelé "Pendentif " ${ }^{87}$ (ill. 3 et 10 ). C'était une chapelle funéraire que le chanoine sacriste de Saint-Apollinaire, Nicolas Mistral, avait eu l'autorisation d'élever en 1548 pour sa sépulture et celle de sa famille. La ville conditionna son aide au fait que la grille, côté Pendentif, demeurerait ouverte au public de même que celle située place des Ormeaux, au sud ${ }^{88}$. Pascal soutint qu'il était nécessaire de fermer par une grille l'accès à l'esplanade livrée au public du côté nord, vers l'escalier descendant à la basse ville. La construction de murs, d'une grille de clôture, d'un escalier de pierre, d'un éclairage au gaz, et d'égouts fut confiée aux entreprises de maçonnerie Arbod

82. La pierre de Puygiron, village situé dans la Drôme provençale, à 9 km à l'est de Montélimar, qualifiée par les géologues de "molasse inférieure" est compacte, craint peu l'action du gel, se travaille facilement et ne noircit pas avec les années.

83. La région du Valbonnais est placée entre les deux routes de Grenoble à Briançon (celle de l'Oisans et celle de La Mure-Gap) et occupe, en plein Pelvoux, les vallées de la Bonne, de la Malsanne et de la Roizonne.

84. Le devis fait état de portes en chêne de $0,054 \mathrm{~m}$ d'épaisseur assemblées à rainures emboîtées des deux bouts. Pour la menuiserie du tambour d'entrée en chêne, les bâtis ont 0,034 m d'épaisseur et les panneaux à deux parements ont $0,020 \mathrm{~m}$ d'épaisseur. Arch. nat., $\mathrm{F}^{19} 7915$, devis des travaux de grosses réparations à effectuer pendant l'année 1903, Pascal, 10 mai 1902.

85. La porte du sud, la plus complète et la plus belle, a conservé un tympan et un linteau malheureusement mutilés en 1562. Au centre du tympan, le Christ, la tête encadrée d'un nimbe crucifere, est assis sur un trône abrité sous un dais. Sa main droite bénit, sa main gauche tient un livre appuyé sur sa poitrine. Aux angles du dais, un aigle et un ange symbolisent saint Jean et saint Matthieu. En bas, un lion et un bœuf symbolisent saint Marc et saint Luc. Le linteau représente la Multiplication des pains. Chanoine Perrot, Noël Thiollier, La Cathédrale de Valence, op. cit., p. 21.

86. Voir note 8 . Arch. nat., $\mathrm{F}^{19} 7915$, devis des travaux de grosses réparations à effectuer pendant l'année 1903, Pascal, 10 mai 1902.

87. Édifice sur plan carré, à toit plat et corniche débordants, ouvert par quatre arcs en plein cintre sur ses faces, qui doit son nom à sa voûte sphérique sur pendentifs. Un description précise, datée de 1833, en est donnée dans "Valence-sur-Rhône ", La Construction moderne, n 22, 24 août 1907, p. 560-561.

88. Arch. nat., $\mathrm{F}^{19} 7915$, lettre du maire de Valence Henri Chalamet au préfet de la Drôme, 8 février 1902. 
et de serrurerie Fuzier, Vellas et Francon ${ }^{89}$. L'éclairage était assuré par des candélabres en fonte et des lanternes rondes en cuivre fondu ${ }^{90}$.

Jean-Louis Pascal s'inscrivait ainsi totalement dans la politique de désenclavement des cathédrales au XIX ${ }^{\mathrm{e}}$ siècle, menée conjointement par les municipalités, qui se lancent alors dans de vastes travaux d'urbanisme pour dégager les édifices publics, élargir la voirie et établir de nouveaux rapports avec le tissu urbain, par l'État, qui désirait assainir les abords immédiats des églises, et par l'évêque, qui tenait à ce que le culte se déroulât dignement et facilement ${ }^{91}$.

89. Les deux soumissions datent du 31 juillet 1903.

90. Les lanternes à gaz avec vitrerie, bec, robinet à levier et brûleur sont semblables à celles posées sur les montants du portail sud; les candélabres de $2,97 \mathrm{~m}$ de hauteur, avec raccords en cuivre, peinture à l'huile trois couches et frottis en bronze à l'antique sont aussi semblables à ceux du parvis sud. Arch. nat., $\mathrm{F}^{19}$ 7915, devis de Pascal du 13 juin 1901.

91. Jean-Michel Leniaud, Les Cathédrales au XIXe siècle, op. cit., p. 441. 